\title{
EN TORNO A LA DÉCADA 1823-1833
}

\author{
M. ${ }^{2}$ Concepción Marcos del Olmo
}

Hubo un tiempo en que la historiografía liberal decimonónica denominaba ominosa década y los trabajos de raíz tradicionalista consideraban pleno de concesiones al disolvente liberalismo. Dos visiones tan distintas como diferentes son los planteamientos políticos que las animan; pero igualmente críticas con un reinado siempre más denostado que verdaderamente conocido e incapaces ambas de atisbar siquiera la riqueza intrínseca de unos años sobre los que aún existen importantes lagunas, considerándose en la actualidad una etapa desconocida en la construcción de la España Contemporánea ${ }^{1}$.

Nadie lo hubiera dicho a mediados del siglo pasado, cuando Federico Suárez Verdeguer analizaba desde planteamientos neopositivistas la crisis política del Antiguo Régimen español y presentaba la época que nos ocupa cual auténtico paradigma reformista, sentando inmejorables bases para un posterior desarrollo monográfico de aquellos hechos y/o factores en los que mejor se avanzaban las líneas de futuro.

La realidad, sin embargo, fue otra muy distinta. Tanto, que hay que esperar a prácticamente nuestros días para que los últimos años del reinado fernandino caminen con paso firme en busca de su más genuina identidad: la propia de una época de transición, en la que arcaísmos de mayor o menor relevancia conviven y se contrarrestan con elementos de renovación y cambio más o menos visibles, dotando al conjunto de un sinuoso perfil, imposible de aprehender desde una única perspectiva, sea ésta la que sea.

\section{HACIA EL APUNTALAMIENTO DE LA "OMINOSA DÉCADA»}

No ha sido fácil llegar al lugar en que hoy nos encontramos. Entre otras cosas porque resaltar la vertiente reformista que efectivamente tienen los años 1823-1833 fue durante mucho tiempo exponerse a una peligrosa identificación

1. Luis, Jean Ph., "La década ominosa (1823-1833), una etapa desconocida en la construcción de la España contemporánean, Ayer, n. ${ }^{\circ} 41$ (2001), pp. 85-117. 
con la tesis de F. Suárez que de forma tan categórica como rigurosa había condenado la renovada historiografía de los años 60-70.

No se nos ocurre mayor descalificación profesional que acusar a un convencido neopositivista de tergiversar el significado de las fuentes utilizadas. Y eso es lo que hacen tanto Carlos $\mathrm{Seco}^{2}$ cuanto Miguel Artola -autor de la más enjundiosa obra de conjunto que sigue teniendo este reinado- al advertir que la consideración del carlismo como una apuesta de reforma a la española es algo que desdichadamente para esta tesis está en la pluma del comentarista y no en el texto comentado?

La tesis de Artola es a este nivel una y muy clara. Entre los naturales de la corte fernandina no existieron más afanes de reforma que los mostrados por el grupo moderado. Y sus propuestas, desoídas pese a coincidir con los planteamientos de la guarnición francesa, apenas si tuvieron alguna traducción práctica: Un decreto de amnistía que destaca, precisamente, por las excepciones que contiene; la aprobación del Código de Comercio en 1829 y poco más ya que ni el Código Penal debió pasar de la fase preparatoria ni el Ministerio de Fomento pudo hacerse realidad antes de la crisis final. Eso sin contar con que Fernando VII ordena la inmediata prisión de quienes no pudieran acogerse al indulto y las comisiones militares reinician sus trabajos poco después de entrar en vigor la mencionada reforma económica. La visión de conjunto se articula por ello sobre la base de dos/tres pilares fundamentales: identificada -en palabras del propio Artola-con politica represiva (...) reiteración de los principios absolutistas(...) y una no menos explicita intención de restaurar el sistema social anterior a la revolución ${ }^{4}$.

Las consecuencias de tan meridiana apuesta emergen con toda crudeza en los trabajos de historia económica. La situación española, en el decisivo momento en que la revolución industrial se extiende por Europa, no puede ser más crítica. Con la pérdida de las colonias, cuyas consecuencias para Cádiz y Sevilla ponían de manifiesto Sánchez Albornoz y García Baquero ${ }^{5}$, se ha cerrado la que fuera tradicional vía de acumulación capitalista sin que la economía española dé síntomas de haber encontrado ningún camino alternativo. No lo es la penetración en el mercado europeo, aunque las exportaciones al extranjero sean el capítulo menos afectado por el profundo declive que según Fontana se vive en estos años ${ }^{6}$. Mucho menos ha de serlo una agricultura básicamente des-

2. En 1955 le acusó de haber montado su hipótesis sobre una falsa base: considerar que la difusa promesa sobre convocatoria de Cortes que realizara Fernando VII en 1814 había sido una imposición al monarca por parte del realismo puro cuando la documentación manejada apunta precisamente en sentido inverso. SeCo, Carlos, "Don Carlos y el carlismo", Revista de la Universidad de Madrid, (1955), pp. 27-52. Cfr. en Tríptico carlista, Barcelona, 1973 pp. 43-44.

3. Artola, Miguel, La España de Fernando VII, Madrid, 1973, p. 886.

4. Ibidem, p. 868.

5. Sánchez Albornoz, Nicolás, "Cádiz bajo la ocupación francesa en 1825", Melanges a la mentoria de Jean Sarrailh II, 1966, pp. 345-353. GarCiA BAOUERO, A., "Independencia colonial americana y pérdida de la primacía andaluza», Historia de Andalucia, vol. VIII, Madrid, 1981, pp. 117-149.

6. FONTANA, Josep, "Colapso y transformación del comercio exterior español entre 1792 y 1827 . Un aspecto de la crisis de la economía del Antiguo Régimen en España", Moneda y Crédito, n. ${ }^{\circ} 115$ (1970), pp. 3-23. 
capitalizada, que compensa sus limitaciones a este nivel con el empleo de una superior fuerza de trabajo, absorbiendo de esta forma el por otra parte limitado crecimiento demográfico y estabilizando en el campo una masa de población tan numerosa como empobrecida, cuya reducida capacidad de compra encorseta sobremanera las posibilidades del comercio interior.

Enmarcada en coordenadas tales, la política fernandina no podía sino considerarse un nuevo y substancial freno a la industrialización del país. Ésta, que dadas las circunstancias, sólo podía emprenderse contando con la tutela estatal y el aporte extranjero, habría quedado virtualmente desechada a medida que Fernando VII anulaba la obra del Trienio; lo mismo cuando se negaba a reconocer la deuda contraída en ese período que al restablecer las fórmulas estamentales. Aquello significa renunciar al capital extranjero, inaccesible en este momento si no es bajo draconianas condiciones; pero volver a las fórmulas contributivas del Antiguo Régimen es, simplemente, condenarse a la inoperancia estatal; obligarse a jugar con unas rentas que ya mostraron insuficientes en el pasado. Máxime ahora que la Tesorería no cuenta con los ingresos extraordinarios que antes procedían de los caudales americanos y la emisión de deuda. Queda -continúa Fontana - el recurso a una creciente presión fiscal pero ésta, amén de actuar cual inmejorable campo abonado para el descontento popular, tiene un límite, tanto más fácil de alcanzar cuanto que los precios medios del trigo se han reducido a prácticamente la mitad entre 1814-18 y 1825-297. Lo conseguido por esta vía no basta para aliviar la angustiosa situación de la Hacienda por lo que se impone una drástica contención del gasto público que muy pronto significa auténtica dejación de funciones. En un momento en que los principales países europeos mejoran sus dotaciones militares, España debe reducir el volumen de su ejército, dejando el grueso de la seguridad interior en manos de esos voluntarios realistas que tan buenos servicios prestaron a la causa del pretendiente. No menos llamativo es el aniquilamiento de las fuerzas navales; una marina reducida a la décima parte de lo que era en el ya decadente año de 1817, que nada podía frente a la acción de los corsarios colombianos que actuaban en aguas españolas y/o las magnitudes que alcanzaba el contrabando. Así es como la lenta agonía de la Hacienda del Antiguo Régimen concluye al decir de Fontana en su muerte por consunción, arrastrando con ella al propio estado de la vieja era ${ }^{8}$.

\section{EL DESCUBRIMIENTO DE LA COMPLEJIDAD: EL VALOR DE LOS INTERROGANTES}

Se habían echado las más sólidas bases para apuntalar la imagen de ominosa década que ya apuntaran los cronistas decimonónicos. Quedaban, sin embargo, varios cabos sueltos y no pocos interrogantes por descifrar. Algunos tan cruciales que hasta podrían decidir una nueva remoción en los cimientos del edificio

7. Ibidem, p. 333 .

8. Ibidem, p. 339 . 
historiográfico. Nos referimos a esa represión que nadie discute, pero merecerá interpretaciones muy distintas según se adapte a uno u otro de los modelos propuestos. Esto es, se concentre en los primeros momentos y esté poderosamente influida por el apasionamiento de los sectores más radicales o se trate de una auténtica operación política alentada desde el propio Trono y servida a través de la maquinaria estatal sin más límites cuantitativos y/o cronológicos que los impuestos por la situación, el propio éxito de la empresa entre otros factores. Ése era, precisamente, el camino a recorrer. Y no sería tan fácil como pudiera pensarse dado que al inicial conocimiento de la legislación antiliberal, desbrozada por los hermanos Peset en $1967^{\circ}$, se interpuso desde muy pronto el más complejo asunto de su puesta en práctica y real aplicación. Se llegó por esa vía a momentos de auténtica tensión interpretativa servidos por Pedro Pegenaute ${ }^{10}$ y su advertencia de que sólo una parte de las causas juzgadas en las comisiones militares se referían a cuestiones políticas; el conocimiento de que estas instituciones limitaron su actuación al breve lapso de tiempo que transcurre entre enero de 1824 y agosto de 1825 , puesto que su reposición durante algunos meses de 1831 no entrañó actividad, o el saber que las Juntas de Purificación zanjaron su cometido con la expulsión de apenas un 10\% de los funcionarios examinados lo que permitió a Jean $\mathrm{Ph}$. Luis calificar la depuración de auténtica utopía reaccionaria ${ }^{11}$.

\subsection{Debates en torno a la represión}

La traslación de estos elementos al gran público, a través de manuales y obras de alta divulgación, hizo el resto: consolidó la idea de polémica, arrastrando hasta nuestros días una controversia más ficticia que real por cuanto se la centra en aspectos que la investigación superó hace ya varias décadas. En realidad desde que Josep Fontana incorporó el concepto de violencia civil alentada desde el poder, refiriéndose a la tensión que soporta el conjunto de la sociedad en el marco de un Estado que institucionaliza el control político y fomenta la delación ${ }^{12}$. La represión incontrolada adquiere entonces una nueva dimensión y el volumen de los represaliados pierde importancia como elemento definidor de un régimen cuya auténtica naturaleza -cosa muy distinta de su real efectividad y/o consecuencias prácticas- se percibe con toda nitidez viéndole actuar en la Extremadura que recrea M. . Jesús Merinero $^{13}$, recordando con Juan Sisinio

9. Peset, Mariano y PeSeT, José Luis, «Legislación contra los liberales», Anuario de Historia del Derecho Español, (1967), p. 437-485.

10. Pegenaute, Pedro, Represión politica en el reinado de Fernando VII: las comisiones militares (1824-25), Pamplona, 1974.

11. Luis, Jean Ph., "Une utopie réactionnaire: l'épuration de l'administration durant la dernière décennie du règne de Ferdinand VII (1823-1833)", Mélanges de la Casa de Velázquez, tomo XXX (3), Madrid, (1994), pp. 7-35.

12. FonTANA, Josep, «Represión política y violencia civil en 1823-1833, propuestas para una interpretación", en Industrialización y nacionalismo (Actas del I Coloquio vasco catalán. Sitges, 20-22 diciembre 1982, Barcelona, 1985.

13. Merinero, M. ${ }^{2}$ Jesús, Purificaciones de empleados públicos. Extremadura, 1824, Cáceres, 1989. 
Pérez Garzón primero y Ramón del Río después la originaria función de los voluntarios realistas ${ }^{14}$ o descubriendo con Juan Francisco Fuentes el papel de la Superintendencia de Policía ${ }^{15}$. Recorriendo, en suma, los distintos instrumentos arbitrados al servicio de un mismo objetivo. El Estado absolutista -resume Jean Ph. Luis en 2001- se transforma (...) en un Estado represivo ${ }^{16}$.

Es una mutación de largo alcance, inconcebible si no es en el marco de las más amplias transformaciones que vive el país en estos años. Auténtico anacronismo, entre otras cosas, de haber sido la oposición liberal esa minoritaria y desarraigada fuerza que pretendió la literatura carlista. La realidad es, necesariamente, más compleja. Al fin y al cabo, el liberalismo demostró inequívoca capacidad de arrastre en 1820 y resistió, aunque no sin dificultades, el embate del absolutismo nacional. No sucumbió, de hecho, sino al arrollador peso de una intervención militar extranjera, auspiciada por las grandes potencias europeas y puesta en práctica por una Francia que -dicho sea de paso- barajó durante un tiempo la posibilidad de llegar a un acuerdo con el liberalismo hispano. No es la actitud que se tiene con los verdaderamente débiles y Gonzalo Butrón Prida ha demostrado recientemente que la política de mezzo termine fue una real, aunque débil y temporal propuesta francesa ${ }^{17}$.

\subsection{Controvertida realidad y renovadas posibilidades del liberalismo}

No debían ser tan despreciables las asistencias y posibilidades del liberalismo español. No lo fueron, de hecho, en el momento decisivo. Está claro que el ejército constitucional se desplomó ante los 100.000 Hijos de San Luis, mostrando todas sus deficiencias y no pocas miserias; pero no puede decirse lo mismo de esas ciudades que seguían en pie de guerra medio año después de que Angulema atravesara los Pirineos. Fue la suya una auténtica resistencia, y presumiblemente más militante que muchas defecciones, debidas en opinión de Sánchez Mantero a las ventajas económicas que reportó la llegada de los franceses antes que a factores de estricta afinidad ideológica ${ }^{18}$. Se acompañó, en cualquier caso, de un voluminoso exilio que desbordó a las autoridades francesas según Sánchez Mantero ${ }^{19}$. Dominaba entre ellos el elemento castrense; pero seguido a escasa distancia por los civiles que se impondrían en un juicio

14. Pérez Garzón, Juan S., "Absolutismo y clases sociales. Los voluntarios realistas de Madrid, 182333", Instituto de Estudios Madrileños, XV (1978), pp. 1-16. DeL Rio ALDAZ, Ramón, "La formación del cuerpo de voluntarios realistas en Navarra (1823-33)", Museo Zumalacárregui. Estudios históricos, n. ${ }^{\circ} 2$ (1992), pp. 209-237.

15. Fuentes, Juan F, "Datos para una historia de la policía política en la década ominosa", Trienio. Ilustración y Liberalismo. Revista de Historia, n. ${ }^{\circ} 15$ (1990), pp. 97-124.

16. Lurs, Jean Ph., "La década ominosa...", p. 93.

17. BUTRón PRIDA, Gonzalo, «La quimera del mezzo termine. La contribución franco-británica a la caída del liberalismo peninsular", Ayer, n. 41 (2001), pp. 63-84.

18. SÁnchez Mantero, Rafael, Los Cien Mil hijos de San Luis y las relaciones franco-españolas, Sevilla, 1981.

19. Sánchez Mantero, Rafael, Liberales en el exilio (La emigración política en Francia en la crisis del Antiguo Régimen), Madrid, 1975. 
ponderado ${ }^{20}$, destacando entre estos labradores y artesanos; sectores populares tradicionalmente ignorados cuya importancia reivindican hoy Dolores Rubio, Antonio Rojas Friend y Juan Francisco Fuentes, enlazando de esta suerte con la politización de grupos subalternos que -según Irene Castells y $\mathrm{M}^{2}$ Cruz Romeo- practica el liberalismo desde $1820^{21}$. Su presencia, aun sin llegar a las cifras que pretende Ana María García Rovira ${ }^{22}$, impide seguir ignorando el efectivo compromiso con la revolución que se da en ciertos sectores de las capas populares. Suelen ser prisioneros de guerra pero el tiempo y las circunstancias los acaban convirtiendo en auténticos exiliados, tanto más comprometidos con la revolución liberal cuanto que su suerte fuera de España está ligada a la solidaridad del conjunto. No sólo de los compatriotas, incluido el helenista Juan Calderón cuya actividad como reformador religioso ha puesto de manifiesto Juan Bautista Vilar ${ }^{23}$; especialmente de ese internacionalismo liberal que ya detectara José Luis Comellas durante el Trienio ${ }^{24}$ y probara, siquiera de forma testimonial la legión organizada en Gran Bretaña que llega a las costas gallegas en la primavera de 1823 .

Enmarcado en estas coordenadas, el exilio español adquiere una nueva y bien enriquecedora dimensión, abriéndose además en distintas direcciones. Una es lo que Irene Castells llama relaciones exteriores; esto es, los contactos y colaboraciones que establece la Junta de Londres con distintos círculos del liberalismo europeo y americano ${ }^{25}$. La otra gran línea de arropamiento transita la alta sociedad británica a través de hombres como Lord Holland, y llega hasta el gobierno de su Majestad, cuyo auxilio económico a Mina se hizo palmaria realidad según los testimonios que recoge Moreno Alonso ${ }^{26}$. Se abren de esta suerte complementarias posibilidades de acción que, ciertamente, ensayará el exilio español en esta época de profundas mutaciones en la que nada es inamovible, incluidos los planteamientos y estrategias del liberalismo. De ahí que la insurrección vía pronunciamiento, única fórmula que se contempla en los primeros tiempos de la Restauración fernandina, sea con posterioridad a 1826 una opción más viva y mejor organizada que nunca, pero limitada en puridad al

20. Rubio, Dolores, Rojas Friend, Antonio y Fuentes, Juan F., «Aproximación sociológica al exilio liberal español en la década ominosa (1823-1833)", Spagna Contemporanea, n. ${ }^{\circ} 13$ (1998), pp. 7 19. Dolores Rubio y Antonio Rojas han vuelto sobre el tema en "Algunas apreciaciones al exilio liberal español en Francia (1823-1833)», en Gil Novales, Alberto, La revolución liberal, Madrid, 2002, pp. 243-250.

21. Castells, Irene y Romeo Mateo, M. ${ }^{a}$ Cruz, "Espacios de poder durante la revolución liberal española: las patrias de los liberales», en GIl Novales, Alberto (ed.), La revolución liberal..., pp. 373-390.

22. Garcia Rovtra, Ana M. ${ }^{2}$, La revolució liberal a Espanya i les classes populars, Vic, 1989.

23. VILAR, Juan B., "El filólogo, helenista y reformador religioso Juan Calderón en la emigración liberal española de 1823-1833», en Antiguo Régimen y liberalismo..., vol. III, pp. 619-626.

24. Comellas, José Luis, El trienio constitucional, Madrid, 1973.

25. CASTELLS, Irene, La utopia insurreccional del liberalismo. Torrijos y las conspiraciones liberales de la década ominosa, Barcelona, 1989.

26. Moreno Alonso, Manuel, La forja del liberalismo en España. (Los amigos españoles de Lord Holland 1793-1840), Madrid, 1997. 
sector que acaudilla Torrijos. Frente a ella se alza, aunque sin seguir una estricta evolución lineal, el pragmatismo de Mina y los círculos más conservadores del exilio, abiertos a cualquier posibilidad -incluido el pacto con el absolutismo más progresivo- que permita romper el «status quo» español. Son actitudes menos utópicas de lo que pudiera pensarse y abren nuevas vías de penetración en la sociedad española, tanto menos despreciables cuanto que su moderada concepción de la revolución coincide con los intereses de la reciclada burguesía.

\subsection{Contra el tópico de las inamovibles actitudes sociopolíticas}

Mucho se ha dicho sobre el papel que jugó este segmento social en el tránsito del Antiguo al Nuevo Régimen; pero está claro que su actitud en la época que nos ocupa carece del impulso revolucionario que tuvo en otro tiempo. Las reducidas dimensiones del grupo, aunque sin llegar a los extremos que en algún momento pretendiera Vicens Vives ${ }^{27}$; sus evidentes limitaciones cualitativas - esa falta de valores propios que detectan Domínguez Ortiz, Anes o Vilar entre $\operatorname{otros}^{28}$... Estaban ahí, pero no impidieron ni su activa participación en los pronunciamientos de la etapa 1814-20, resaltada por J. Fontana como argumento probatorio de su tesis ${ }^{29}$ pero igualmente documentada en Comellas ${ }^{30}$, ni esa radical alianza con el campesinado -en su común lucha antiseñorial- que Antonio Miguel Bernal retrotrae a los años sesenta del siglo XVIII. ${ }^{31}$ Ahora, en cambio, se juega a la colaboración. Y no sólo en la recta final del período, cuando ofrezca -según Pere Anguera- su activo concurso a la Pragmática Sanción ${ }^{32}$.Ya antes de que el cambio se vislumbrara efectivo y posible, la burguesía catalana dio un voto de confianza al Gobierno, confirmándose el pacto tácito con el rey-dice Irene Castells-al ofrecerle su apoyo económico y político en la lucha contra los apostólicos en $1827^{33}$. El camino hacia la "solución pactada" que culmina en 1836-37 se inicia, pues, con anterioridad al pleito dinástico y nada indica que se nutra de simples claudicaciones. La burguesía ha saboreado las mieles del poder entre 1820-1823 y eso -estamos de acuerdo con Irene Castells- es preludio de moderación.

27. VICENS VIVes, Jaume, Coyuntura económica y reformismo burgués, Barcelona, 1974.

28. Dominguez Ortiz, A., La sociedad española del siglo XVIII, Madrid, 1955; Sociedad y Estado en el siglo XVIII español, Barcelona, 19760 "La sociedad española en el tránsito del siglo XVIII al XIX", en VV. AA., España a finales del siglo XVIII, Tarragona, 1986. ANES, G., Economía e llustración en la España del siglo XVIII, Madrid, 1969 o El Antiguo Régimen: Los Borbones, Madrid, 1975. VILAR, P., "La España de Carlos III", en España a finales del siglo XVIII.

29. FONTANA, Josep, La quiebra de la Monarquia absoluta, Barcelona, 1971.

30. Comeilas, José Luis, Los primeros pronunciamientos en España, Madrid, 1958.

31. Bernal, Antonio Miguel, «Señoritos y jornaleros: la lucha por la tierra», Historia de Andalucía, vol. VIII, pp. 217-295. La propiedad de la tierra y las luchas agrarias andaluzas, Barcelona, 1974.

32. AnCuera, Pere, "Cataluña ante la pragmática de 1830 y la amnistía de 1832 ", en FerNÁNDEZ Albadalejo, P. y Ortega López, Margarita (eds.), Antiguo Régimen y liberalismo. Homenaje a Miguel Artola, 3. Politica y cultura, Madrid, 1995, pp.49-58.

33. Castelis, Irene, La utopía insurreccional del liberalismo,... p. 255. 


\section{HACIA LA REVALORIZACIÓN DEL COMPONENTE REFORMISTA}

\subsection{Alcance y significado de las legislaciones socioeconómica y educativa}

Existe, sin embargo, la otra cara de la moneda. Y se hace de iniciativas gubernamentales tan significativas como el hecho de no reponer la jurisdicción señorial. Porque defender el valor simbólico de la misma, como en su día hicieran Vilar, Domínguez Ortiz, Anes o Antonio Miguel Bernal, es olvidar las pruebas en contra que, a su vez, han ofrecido Ardit o Ruiz Torres entre otros ${ }^{34}$. Y no es la única novedad que registran estos años en los que López Ballesteros racionaliza la gestión de las finanzas públicas; se impulsa la producción nacional mediante el arancel general de 1825 , la ley de minas aprobada ese año cuya virtualidad, hoy nuevamente reivindicada por Chastagnaret ${ }^{35}$, se deja sentir en lo que Nadal denominó minería penibética ${ }^{36}$ y emerge con fuerza en los trabajos de García Montoro sobre la siderurgia malagueña ${ }^{37}$, o la creación del Ministerio de Fomento y se crea un embrionario sistema financiero en torno al Banco de San Fernando, la Bolsa de Madrid y ese Código de Comercio cuyo carácter progresivo, incluso desde la futura perspectiva liberal, puso de manifiesto Tortella Casares en su trabajo sobre el principio de responsabilidad limitada ${ }^{38}$.

Son medidas puntuales, de efectos tanto más limitados cuanto que inscritas en el marco de estructuras claramente antiguo-regimentales, llamadas en última instancia a preservar el «status quo» socio-político, pero finalmente renovadoras y en modo alguno despreciables. Aunque sólo sea porque el crecimiento industrial español arranca de estas fechas, según la coincidente opinión de Nadal y Sánchez Albornoz ${ }^{39}$, confirmando que las relaciones de producción capitalista -tal como apuntara Artola ${ }^{40}$ - preceden a la revolución liberal-burguesa; cuyo fracaso - dicho sea de paso y para mayor abundamiento- domina el panorama historiográfico español de los años 70-80 aún cuando no falte quien defiende la radicalidad que tuvo la revolución española ${ }^{41}$. Se abría paso la tesis de una gradual modernización, aplicada primero al terreno económico y más tarde in-

34. ARDT, Manuel, Revolución liberal y revuelta campesina: un ensavo sobre la desintegración del régimen feudal en el País Valenciano (1793-1840), Barcelona, 1978. Ruiz ToRres, Pedro, «Algunos aspectos de la revolución burguesa en España», WV. AA., El jacobinisme. Reacció i revolució a Catalunya i a Espanya, 1789-1837, Barcelona, 1990, pp. 9-39.

35. Chastagnaret, Gérard, "La construcción de una imagen reaccionaria: la política minera de la década ominosa en el espejo liberal», Ayer, n. ${ }^{\circ} 41$ (2001), pp. 119-140.

36. NADAL, Jordi, "Industrialización y desindustrialización del Sureste español, 1817-1913», Moneda y Crédito, n. ${ }^{\circ} 120$ (1972), pp. 3-80.

37. García Montoro, Cristóbal, "La siderurgia de Río Verde y la deforestación de los Montes de Marbella", Moneda y Crédito, n. ${ }^{\circ} 150$ (1979), pp.79-95.

38. TORTELla Casares, Gabriel, "El principio de responsabilidad limitada y el desarrollo industrial en España, 1829-1868", Moneda y Crédito, n. ${ }^{\circ} 104$ (1968), pp.69-84.

39. NADAL, Jordi, El fracaso de la revolución industrial en España (1814-1913), Barcelona, 1975. SANCHEZ Albornoz, Nicolás (comp.), La modernización económica de España, 1830-1930, Madrid, 1985.

40. Artola, Miguel, Antiguo Régimen y Revolución liberal, Madrid, 1978.

41. Vid. en ese sentido Ciavero, B., Ruiz Torres, P. y Hernández Montalbán, F. J., Estudios sobre la revolución burguesa en España, Madrid, 1979. 
cluso al político, de la que aún hoy somos deudores. Y con ello llegaba la doble "rehabilitación» que supone valorar la herencia reformista que Fernando VII incorpora como tradición a su reinado ${ }^{42}$ e incidir en sus propias aportaciones. Algo más que la legislación económica del período gana enjundia al calor de esta nueva perspectiva dado que uniformidad y centralización son los principios inspiradores de unas leyes educativas cuyo básico continuismo respecto del Trienio ya puso de manifiesto Ruiz Berrio ${ }^{43}$ en 1970.

\subsection{El entramado administrativo}

El otro gran centro de interés está en la Administración; ese conjunto institucional -en palabras de Jover-a través del cual el poder político transmite unas decisiones, impone coactivamente unos comportamientos, controla una sociedad ${ }^{44}$. Fue durante años la gran olvidada de la Historia, a pesar de la semilla que plantara Federico Suárez en los años $40^{45}$; la importancia que adquiría la administración josefina en los trabajos que publicaba Mercader Riba a finales de los años cincuenta ${ }^{46}$ o de que Vicens Vives se hiciera con la estructura administrativa estatal de los siglos XVI y XVII ${ }^{47}$. El interés fue en aumento. El tema se enriqueció con las aportaciones de Domínguez Ortiz, González Alonso, Martínez de Velasco, Guaita, Escudero o González Mariñas en los años $70^{48}$ y de García Fernández, Calero Amor, Morales Moya, García Madaria, Bermejo Cabrero, Tomás y Valiente, Fontes Migallón y Molas Ribalta en los $80^{49}$. Pero seguía básicamente vinculado al derecho administrativo.

42. Anes, Gonzalo, Tedde, Pedro, Fontana, Josep y Artola, Miguel (dirs.), La economía española al final del Antiguo Régimen. 1. Agricultura. 2. Manufacturas. 3. Comercio y colonias. 4. Instituciones, Madrid, 1982.

43. Rurz Berrio, J., Política escolar de España en el siglo XIX (1808-1833), Madrid, 1970.

44. JOVER, J. M. ${ }^{2}$, "Política y civilización en España, 1834-1874", en La civilización española a mediados del siglo XIX, Madrid, 1992, p. 97.

45. SuÁrez, F., "La creación del Ministerio del Interior en España", Anuario de Historia del Derecho español, n. ${ }^{\circ} 19$ (1948-49), pp. 15-56.

46. MerCADer Riba, J., "La organización administrativa francesa en España», en Congreso de la Guerra de la Independencia y su época, Zaragoza, 1959.

47. ViCENS VIVES, J., "Estructura administrativa-estatal de los siglos XVI y XVII», en Coyuntura económica y reformismo burgués, Barcelona, 1968, pp. 124-126.

48. Dominguez Ortiz, Antonio, Sociedad y Estado en la España del siglo XVIII, Barcelona, 1976. MARTínez DE VelasCo, A., La formación de la Junta Central, Pamplona, 1972. GuATTA, A., "La división provincial y sus modificaciones", en Actas del II Simposium de Historia de la Administración, Madrid, 1971, pp. 309-322. EsCudero, J. A., Los origenes del Consejo de Ministros. La Junta Suprema de Estado, Madrid, 1979. González Mariñas, P., Génesis y evolución de la Presidencia del Consejo de Ministros en España, 1808-1875, Madrid, 1974.

49. García Fernández, Javier, El origen del municipio constitucional. Autonomia y centralización en Francia y España, Madrid, 1983. CAlero AMOR, Antonio M., La división territorial de 1833. Bases y antecedentes, Madrid, 1987. Morales Moya, Antonio, «Política y administración en el siglo XVIII (Notas para una sociología histórica de la Administración Pública)", Revista de Administración Pública, 105 (1984), pp. 167-200. GarCía MADARia, J., Estructura de la Administración Central, 1808-1931, Madrid, 1982. Bermejo CABrero, J. L., Estudios sobre la Administración Central Española (siglos XVIIXVIII), Madrid, 1982. TOMÁs Y VALIENTE, Francisco, "Legislación liberal y legislación absolutista sobre funcionarios y sobre oficios públicos enajenados: 1810-1822*, en Actas del IV Symposium 
Hay que esperar a la década de los 90 para que se opere la auténtica inflexión, integrándose la Administración en el análisis general de la época, situándose en pie de igualdad con las transformaciones socioeconómicas cuando de valorar la naturaleza del cambio operado se trata, y, lo más importante, dotada ya de una auténtica interpretación histórica. Ése es el trabajo que realizara Mariano Esteban de Vega ${ }^{50}$, perfilando los contornos que hoy tiene el tema. Su labor de síntesis, obligada referencia en la actualidad, confirma aquella tesis de Francisco Tomás y Valiente según la cual el liberalismo triunfante no habría necesitado construir el Estado, que existía ya en la Monarquía absoluta, sino otro Estado ${ }^{51}$ : basado en la división de poderes, entre otras substanciales diferencias que el profesor Esteban de Vega deja bien sentadas, pero tanto más deudor del pasado cuanto que uniformidad, centralización y racionalización administrativa -los grandes ejes que articulan el Estado liberal- son fácilmente detectables en su homólogo ilustrado, lanzado entre otras cosas a la sustracción del poder político a los Ayuntamientos que desarrollará, aunque no concluirá a juicio de Hijano Pérez, el régimen liberal ${ }^{52}$. Ahí está el otro gran referente: ese pasado que Morales Moya resumiera en 1992 para los asistentes al I Congreso de Historia Contemporánea de España ${ }^{53}$; y Mariano Esteban asume de forma tan explícita como reiterada. Es la única forma de no tergiversar el sentido de unas medidas tan poco originales como a la postre decisivas; meros eslabones de una cadena cuyo diseño se remonta a los albores del siglo XVIII -aunque el grueso de su trabazón llegue en la segunda mitad de la centuria- pero se consolida durante el reinado fernandino, de forma muy especial aunque no exclusiva, en la última parte del mismo. A pesar de las vacilaciones, pasos atrás y alguna que otra contradicción, fiel reflejo de la última gran variable a considerar: las reactivadas luchas de poder. En ese contexto, al que ya remitía Juan Francisco Fuentes ${ }^{54}$ para entender el papel de la Superintendencia General de Policía, se enmarca también el frustrado intento de sustraer al poder militar la persecución

de Historia de la Administración, Madrid, 1983, pp. 703-722. Molas RibalTA, P., «De la Junta de Comercio al Ministerio de Fomento», Ibidem, pp. 529-556.

50. Esteban de VeGA, Mariano, "El reinado de Fernando VII», en Morales Moya, Antonio (coord.), Las bases politicas, económicas y sociales de un régimen en transición (1759-1834), Madrid, 1998, pp. 235-334. EsTebAN DE VEGA, Mariano, "El Estado y la Administración central en el reinado de Fernando VII", Historia Contemporánea, n. ${ }^{\circ} 17$ (1998), pp. 81-117.

51. Tomás y VALIENTE, F, "Lo que no sabemos acerca del Estado liberal (1808-1868)», en Antiguo Régimen y liberalismo. Homenaje a Miguel Artola. 1. Visiones generales, Madrid, Alianza-Universidad Autónoma, 1994, p. 138.

52. Hijano Pérez, M. ${ }^{2}$ Ángeles, «La pérdida del poder político en los Ayuntamientos tras la revolución liberal", en Antiguo Régimen y liberalismo. Homenaje a Miguel Artola, vol. 3, Madrid, 1995, pp. 163-173. También El pequeño poder. El municipio en la Corona de Castilla. Siglos XV al XIX, Madrid, 1992.

53. Morales MoXa, Antonio, "Los orígenes de la Administración Pública contemporánea», en MoRales Moya, Antonio y Esteban de VEGA, Mariano (eds.), La historia contemporánea en España, Salamanca, 1992, pp. 53-72.

54. Fuentes, Juan F., "Notas para una historia de la policía política de la década ominosa»..., pp. 97-124. 
del contrabando ${ }^{55}$-reforzando así la militarización del gobierno territorial que consolidará el Estado liberal.

El cuadro resultante es un «sistema de poder dentro de la crisis del Antiguo Régimen español»-dice Mariano Esteban- que vendría definido por el ya irreversible declive del sistema polisinodal, cuya crisis se agudiza de forma decisiva tras perder el Consejo Real de Castilla su control sobre las haciendas locales y quedar el de Estado definitivamente relegado ante un Consejo de Ministros que no en vano refuerza su estructura, regula y periodiza sus sesiones, adquiere en la práctica un cierto poder decisorio y hasta se atenúa su dependencia del rey con posterioridad a la última crisis del reinado.

Todo para mejor garantizar la supervivencia del absolutismo, sí; pero modificando el funcionamiento del sistema, introduciendo pautas que desarrollará el liberalismo, y no pudiendo obviar las efectivas implicaciones políticas de algunas medidas, el reforzamiento gubernamental que late bajo la gestión del Presupuesto Estatal por ejemplo. Su puesta en práctica no es, por lo demás, ni prueba de la conspiración que pretendía F. Suárez, ni exclusivo fruto de las presiones exteriores por mucho que el arreglo de la Administración ocupe un lugar prioritario entre los consejos que dan a Fernando VII las potencias signatarias de la Santa Alianza.

\subsection{Variedad e importancia de los impulsos nacionales}

Está claro el papel de las potencias extranjeras: sus propuestas, reiteradas llamadas a la moderación, y su afân de tutelar la Restauración española; pero también el fracaso de su actividad negociadora, reconocido por ellas mismas ${ }^{56}$. Eso sin contar con que la Conferencia de Embajadores se colocó al lado de la Regencia en su oposición a la "Ordenanza de Andújar» (8/8/1823), lo que -tiene razón Ulrike Schmieder- es un «apoyo (...) a la causa de la reacción absolutista ${ }^{57}$. Y que lo haga de forma menos violenta de lo que cabía esperar en palabras de R. Sánchez Mantero ${ }^{58}$ es prueba de su intrínseca debilidad antes que reflejo de su moderada actitud político-ideológica, relegada a segundo término cuando de evitar el excesivo predominio francés se trataba.

En cuanto a Francia, su capacidad de intervención en los asuntos internos del país se hizo por demás patente en esa «Ordenanza de Andújar» que -sencillamente- colocaba al ejército galo por encima de las autoridades españolas en el espinoso asunto de la represión. Y se mantuvo, aunque adaptada a la nueva situación, una vez que Fernando VII toma las riendas del país. No podía ser de otra forma dada la indefensión del monarca; su dependencia respecto de la fuerza militar francesa, que no en vano se mantuvo como ejército de ocupación

55. EsteBAN DE VeCA, Mariano, "El reinado de Fernando VII»..., p. 316.

56. SCHMIEDER, Ulrique, "Las grandes potencias y la Restauración española, 1823-1824", Trienio, n. ${ }^{\circ}$ 19 (1992), pp. 143-164.

57. Ibidem, p. 152.

58. Sanchez Mantero, Rafael, Los Cien Mil Hijos de San Luis..., p. 102. 
hasta 1828. Se pudo, en consecuencia, «aconsejar» el cese del canónigo Sáez en diciembre de 1823, promover la amnistía en los primeros meses de 1824 y aparecer siempre ante los ciudadanos como efectiva garantía de amparo frente a los excesos reaccionarios ${ }^{59}$. Ahora bien, valorar en su justa dimensión el resultado de la intervención francesa pasa por saber que Angulema abandona el país en noviembre de 1823 sin despedirse siquiera de Fernando VII -inequívoca prueba de la decepción que arrastra-; que el Gobierno no reconoce la deuda del Trienio pese a la insistente presión francesa o que el decreto del 1 de mayo de 1824 contiene tantas excepciones que en realidad no amnistía a casi nadie.

En cualquier caso, Francia asume el fracaso de su proyecto político en España mucho antes de lo que a veces se piensa, centrándose con posterioridad a mayo de 1824 -y ahora con el inequívoco éxito que ya demostrara Sánchez Mantero, en el otro objetivo que tuvo la expedición de Angulema: la conversión de España en un mercado semi-reservado a los intereses económicos franceses. Sin embargo, las reformas continúan -con más fuerza que antes, apostilla Jean Philippe Luis ${ }^{60}$ - lo que obliga a considerar la existencia de otros impulsos, aunque sólo sea el que hace de la necesidad virtud. La realidad es a este nivel una y muy clara, aún contando con que la pérdida de los mercados coloniales no tuvo las generales consecuencias y desastrosos efectos que inicialmente se creyó. Trabajos como el de Leandro Prados ${ }^{61}$ inducen a reconsiderar el papel de los distintos elementos en juego; pero no llegan a cuestionar la crítica situación de la Hacienda Pública. Las finanzas amenazan quiebra y la única forma de evitar el colapso es una drástica reducción de gastos, unida a un férreo control.

Las circunstancias mandan. Y explican de forma harto convincente una actividad reformadora que no sólo existe, transitando a modo de Guadiana la totalidad del período, y deja su impronta más allá de lo que en algún momento se pensó. Tiene, además, la virtualidad de traspasar fronteras ideológicas, abriéndose paso, incluso entre los sectores más intransigentes del Gobierno. Es el caso paradigmático de un Tadeo Calomarde cuya significación ultraderechista no es óbice para que su obra de gobierno incluya una ordenación territorial que Jesús Burgueño ha considerado auténtico eslabón perdido entre la división de Cortes de enero de 1822 y la decretada por Javier de Burgos en noviembre de $1833^{62}$. El punto de partida no es otro que las graves disfunciones detectadas en una Administración de Justicia literalmente desbordada ahora que, al no reponerse la jurisdicción señorial, el Estado debe llegar a todos los rincones del país. Y el resultado, un acabado plan de división territorial que Javier de Burgos pudo

59. Vid. en este sentido Sánchez Mantero, Rafael, Los Cien Mil Hijos de San Luis..., p. 112.

60. Luis, Jean Ph., «La década ominosa (1823-1833), una etapa desconocida en la construcción de la España contemporánea"..., p. 101.

61. Prados, Leandro, "Comercio exterior y cambio económico en España (1792-1849)", en La economía española al final del Antiguo Régimen..., vol. III, pp. 175-249.

62. Burgueño, J., Geografía politica de la España constitucional. La división provincial, Madrid, 1996, p. 145. 
rescatar del olvido, presentándolo al Consejo de Ministros en octubre de 1833 y convirtiéndolo un mes después en carta administrativa liberal.

La posición que ocupa el Secretario de Gracia y Justicia es de todos conocida. Todo lo que hicieron las llamadas Cortes -afirma en alguna ocasión- lleva sobre sí una funesta impresión ${ }^{63}$. Sin embargo, la comisión creada en 1825 -encargada de estudiar el arreglo de tribunales de provincias, juzgados inferiores y alcaldias mayores $^{64}$ - incluye a Larramendi, un antiguo colaborador del Gobierno constitucional, y no rechazó el fruto de su trabajo pese al desasosiego que debía crear en su conciencia de realista puro.

No faltaban, sin embargo, impulsos de mayor calado y superior congruencia política. La idiosincrasia de muchos colaboradores fernandinos es clara en este sentido. López Ballesteros, Sainz de Andino, Javier de Burgos... Todos tienen experiencia previa siguiendo una tendencia que $M{ }^{a}{ }^{a}$ Victoria López Cordón ha demostrado extensible a los oficiales y agentes diplomáticos ${ }^{65}$, y más homogénea de lo que pudiera parecer a juzgar por su distinto pasado político. Fueron afrancesados o servidores de la España patriótica, adscritos a la Junta Central y las Regencias ${ }^{66}$, pero siempre en calidad de técnicos y compartiendo una misma formación, de raigambre ilustrada, que imprime carácter: genera similares preocupaciones y lleva a coincidentes soluciones. Su mundo es el de la burocracia dieciochesca, renovada por la experiencia napoleónica; su horizonte, ese liberalismo económico que tan claramente percibiera García Madaria en el pensamiento administrativo de Sainz de Andino ${ }^{67}$, y su ideal político, una monarquía absoluta que favorezca el crecimiento económico nacional jugando -en palabras de Antonio Elorza- con una administración que actuara sin trabas favorecida por la despolitización del pais ${ }^{68}$.

Explícitamente partidario de las reformas es, a su vez, el llamado subgrupo de los diplomáticos, en el que se incluyen el Marqués de Casa-Irujo, Cea Bermúdez o ese Conde de Ofalia que comparando la realidad española con la de Francia e Inglaterra concluía tajante: nosotros mismos, y nosotros solos, somos los que podemos, mejorando nuestro sistema administrativo, labrar nuestra felicidad ${ }^{69}$.

Son impulsos por demás reales, que nacen de la convicción aunque se desarrollen al calor de las necesidades, y tanto más susceptibles de ampliación cuanto que sus llamadas a la amnistía enlazan directamente con las aspiraciones de ese grupo que Recacho llamaba constitucionales pacíficos. Son gentes -especifica el Superintendente de Policía- sin otro compromiso con el fenecido orden que su circunstancial e interesada colaboración durante el Trienio; pero

63. Ibidem, p. 147.

64. Ibidem, p. 140.

65. López CORDÓn, $M^{a}{ }^{a}$ Victoria, "Coyuntura política y continuidad institucional: oficiales y agentes diplomáticos (1793-1825)", en Antiguo Régimen y Liberalismo..., vol. III, pp. 189-208.

66. EsTEBAN DE VECA, Mariano, "Cambios y permanencias en la elites políticas y administrativas del reinado de Fernando VII», Historia Contemporánea, n. ${ }^{\circ} 12-13$, pp. 229-237.

67. García Madaria, J. M. ${ }^{a}$, El pensamiento administrativo de Pedro Sainz de Andino. Sevilla, 1982.

68. EloRzA, A., La modernización politica de España. Madrid, Endymion, 1990, p. 218.

69. Cfr. en Artola, M., La España de Fernando VII, p. 884. 
también liberales de opinión desengañados ante el radicalismo de los últimos tiempos. Moderados al estilo de Miñano, Gómez Hermosilla o Lista cuyo afán de integración en la restaurada Monarquía Absoluta se hace patente desde el primer momento.

Existe, resumiendo, todo un ambiente reformista; hecho de precisos intereses y confluyentes actitudes, cuyas formulaciones bien pudieran resumirse al modo que lo hicieron Javier de Burgos en su famosa Exposición o José Manuel Regato a finales de 1826. No son, sin embargo, ni el partido que creyera Carnerero en el momento de los hechos, ni fieles servidores de un plan preconcebido como apuntaba Suárez. Son un globuloso mundo, menos cohesionado de lo que sus múltiples contactos hicieran pensar, cuyas propuestas resultan más interesantes que verdaderamente atractivas; incapaces de generar, por su propia naturaleza gradualista, la entusiasta adhesión que despiertan, en cambio, opciones políticas más rotundas e incisivas: Lo mismo el liberalismo, salvadas todas las distancias, que ese absolutismo intransigente, autoconvertido en depositario de las esencias antiguorregimentales, que considera connivencia con el liberalismo todo lo que no sea borrar la huella de los años 1820-1823 y volver a la situación pre-revolucionaria.

\section{VECTORES DE LA INFLUENCIA ULTRARREALISTA}

Se trata de un ultrarrealismo trasnochado, al que la realidad hace navegar contra corriente, pero enormemente activo, que opera a través de las Juntas de Fe lo mismo que en el marco de sociedades secretas que ya identificara Del Moral ${ }^{70}$ y juega la baza del complot al tiempo que se procura la movilización popular.

No tiene, ni mucho menos, las dimensiones que alcanzará el carlismo una vez que el pleito dinástico proporcione lo que Gloria Martínez Dorado y Juan Pan Montojo califican de auténtica oportunidad política ${ }^{71}$. Sin embargo, logra clientelas específicas en esta época de cambios en la que se revisan las exenciones forales -con evidente éxito en Navarra y efectiva resistencia en las tres provincias vascas según apuntan $\mathrm{M}^{2}{ }^{\mathrm{a}}$ Cruz Mina y Coro Rubio ${ }^{72}$ - y el mantenimiento de las fórmulas estamentales es compatible con la solicitud de fuertes sumas al clero, cuya entrega tiene poco de voluntaria según ha comprobado Carlos M. Rodríguez López-Brea para la etapa 1814-182073. La instrumentalización política llega, por lo demás, a la protesta catalana de 1827, actuando a

70. Del Moral. Ruiz, J., "Las sociedades secretas ultrarrealistas de España y Portugal (1821-1832)», Sistema, n. ${ }^{\circ} 8,1975$.

71. Martinez Dorado, G. y Pan Montojo, J., "El primer carlismo, 1833-1840", Ayer, n. 38 (2000), pp. 35-63, especialmente pp. 54 y ss.

72. Mins, M. ${ }^{a}$ Cruz, Fueros y revolución liberal en Navarra, Madrid, 1981, pp. 107-110. Rubio Pobes, Coro, "Liberalismo y Revolución en el País Vasco, 1808-1868" en Gli Novales, Alberto, La Revolución Liberal..., pp. 263-278.

73. Rodriguez López-BreA, Carlos M., "¿Alianza entre Trono y Altar? La Iglesia y la política fiscal de Fernando VII en la diócesis de Toledo (1814-1820)», Spagna Contemporanea, 19 (2001), p. 36. 
través de los voluntarios realistas -más que descontentos por el atraso en sus pagos-y contando con el malestar de unos campesinos afectados por algo más que el general desplome de precios y la creciente presión fiscal dada la específica crisis que, según Emiliano Fernández de Pinedo, vive el mercado de los aguardientes catalán y valenciano ${ }^{74}$.

Cuentan, finalmente, con significativos resortes del poder institucional. Y ello porque los reformistas no tendrán el decidido apoyo de la Corona sino en fechas muy tardias. De hecho, ni el influjo del absolutismo moderado sigue en la década de los veinte el lineal ritmo ascendente que pudiera pensarse ni la visibilidad que adquiere en determinados momentos de ese tracto cronológico logra ocultar el carácter, en realidad poliédrico, de la acción gubernativa. Sirva de ejemplo lo ocurrido entre julio de 1824 y octubre de 1825 cuando la reforma de las enseñanzas universitaria y primaria, verdadera manifestación del espíritu ilustrado que encarnan Cea Bermúdez y buena parte de los ministros, se contrarresta con la creación de las primeras Juntas de Fe, auténtico remedo de la extinta Inquisición, y la reglamentación de ese cuerpo de voluntarios realistas al que José $M .{ }^{2}$ Ortiz de Orruño responsabiliza del activismo popular armado que se desarrolla en determinadas sociedades agrícolas ${ }^{75}$.

La actitud de Fernando VII se hace clara a este nivel. Es la suya una política de pesos y contrapesos, gracias a la cual conservan significativas parcelas de poder los Calomarde, Carvajal, Duque del Infantado, Erro y demás representantes de ese absolutismo intransigente cuyos miembros, más realistas que el Rey en un primer momento, se hicieron pronto realistas contra el Rey.

Está claro, en cualquier caso, que el ultrarrealismo posee una capacidad de acción muy superior a la derivada de su actividad conspirativa y/o estrategia movilizadora toda vez que el dosificado-pero real-apoyo de la Corona permite una paralela imbricación en los círculos de poder "oficial" cuyas repercusiones a nadie pasan desapercibidas. Es posible que se trate de un círculo vicioso ya que el factor miedo es al menos un elemento a tener en cuenta, pero el resultado, con independencia de los motivos, es uno y muy claro. La oposición digamos institucional del ultrarrealismo está en la base del retraso y/o desnaturalización que sufren algunas de las más significadas iniciativas reformistas. Conviene recordar en este sentido que la definitiva institucionalización del Consejo de Ministros llega tras ardua lucha de poder con el Consejo de Estado; que el Ministerio de Fomento, incluido en la propuesta que hace Javier de Burgos, no se aprueba sino años después de que el Gobierno urgiera su creación y el propio Fernando VII se mostrara dispuesto a la concesión; o que la Superintendencia General de Policía, pieza clave en estas luchas de poder según Juan Francisco

74. Fernández de Pinedo, Emiliano, "La recuperación del comercio español con América», en Antiguo Régimen y liberalismo..., vol. I, pp. 51-66.

75. Ortiz de Orruño, José M., "La militarización de la sociedad vasca en el tiempo de paz: los naturales armados (1823-1833)», Vasconia, 26 (1998), pp. 23-40. 
Fuentes $^{76}$, cae bajo la órbita política de Calomarde tras quedar adscrita al Ministerio de Gracia y Justicia en agosto de 1827.

\section{EL POSTRERO REFORZAMIENTO DE LOS LIBERALES}

Otra cosa es que a fuerza de identificarse con el Antiguo Régimen, de luchar en defensa de unos derechos que legitiman el orden social, aunque no se vinculan a un orden definidamente feudal según Jesús Millán ${ }^{77}$, el ultrarrealismo acabe coadyuvando, incluso de forma harto decisiva, a la definitiva superación del absolutismo. Por demás reseñable es en este sentido la división que se opera en el interior de los grupos privilegiados; especialmente desde que la guerra de los agraviados pone de manifiesto el potencial subversivo que encierra la contrarrevolución, lo cual es toda una llamada de atención para importantes sectores de la aristocracia que, llevados del más puro conservadurismo, acaban en brazos de un liberalismo que al menos garantiza el mantenimiento de sus propiedades. El ultrarrealismo se perfila de esta suerte cual decisivo elemento de juicio a la hora de explicar la tramitación y específica resolución que tuvo la crisis del Antiguo Régimen español. Así se explica, por lo demás, la a su vez tremenda paradoja de un reformismo que vio obstaculizada su labor por una fuerza política supuestamente inferior y acabó desbordado por otra de similares características en origen.

No se trata de negar las limitaciones del absolutismo moderado; encerrados al fin y a la postre en la última contradicción de unas reformas que erosionan cuando menos los fundamentos de la estructura que se pretende conservar. Está claro, sin embargo, que esas limitaciones se vieron amplificadas en el marco de la mencionada política fernandina; por el hecho, para ser más exactos, de no contar con el decidido apoyo de la Corona sino en presencia de una nueva $-y$ ahora sí, decisiva- necesidad: asegurar la sucesión femenina.

El punto de inflexión llega con los "Sucesos de La Granja", que no con la «Pragmática Sanción» y el nacimiento de Isabel II por mucho que a estos acontecimientos siga lo que Artola ha considerado reconocimiento vergonzante de las deudas contraídas en el Trienio ${ }^{78}$. Es, nadie lo duda, inequívoca concesión al programa de los moderados pero contrarrestada, siguiendo pautas al más puro estilo fernandino, con un nuevo impulso represivo. Hay que esperar a octubre de 1832 para que, comprobadas de forma fehaciente las dificultades que presenta la causa isabelina, se entre en una fase de auténtica y acelerada política reformista que muy pronto traspasa las fronteras de lo estrictamente administrativo.

Mucho se ha especulado sobre la inclinación liberal de $M{ }^{a}$ Cristina, atribuyendo a esta preferencia ideológica -supuestamente fomentada por sus hermanos- la rápida transición hacia el liberalismo que se opera durante su etapa al

76. Fuentes, Juan F., "Datos para una historia de la policía política en la década ominosa”..., p. 109.

77. MiLlấn, Jesús, «Una reconsideración del carlismo", Ayer, 29, p. 98.

78. ARTOLA, M., La España de Fernando VII, p. 901. 
frente del país. No se duda en la actualidad de la influencia que ejercieron sobre ella su hermana Luisa Carlota y su doblemente cuñado, el infante don Francisco de Paula; pero difícilmente pudieron inculcarle unos postulados que, según Moral Roncal ${ }^{79}$, no estaban por esas fechas en el ánimo del infante. El interés de madre, y las necesidades de él derivadas se perfilan, en cambio, como alicientes más que suficientes para explicar unas decisiones que tampoco transgredían inicialmente el horizonte del más puro absolutismo moderado. Otra cosa es que las especiales circunstancias del momento confieran al programa reformista unas claras implicaciones políticas que, ahí está la última paradoja, sólo en detrimento de su propia viabilidad acabarán redundando. Poco importa, dicho con otras palabras, que Cea Bermúdez siga fiel a los esquemas del despotismo ilustrado porque las simples reformas administrativas carecen de sentido en un momento en que la levantisca actitud del carlismo, obliga a incrementar la fuerza del ejército regular y hacerse con el revalorizado apoyo liberal exige concesiones de más largo alcance. Así se hace, ciertamente. El decreto de Ayuntamientos aprobado en febrero de 1833 es ya una puerta abierta a la integración burguesa, pese al evidente riesgo que entraña. El reformismo absolutista ha perdido el control de la transición antes de que la guerra carlista, prueba en sí misma del fracaso, lo entierre definitivamente.

79. Moral Roncal, Antonio M., "Los límites de un mito liberal: El infante don Francisco de Paula Borbón", Trienio, n. ${ }^{\circ} 34$ (1999), pp. 113-135. 